\title{
Turismo de carretera en el Perú. Oportunidades y desafíos
}

\author{
Road tourism in Peru. Opportunities and challenges
}

\author{
Fabrizio Augusto Alberca Sialer* \\ Escuela Profesional de Turismo y Hotelería, \\ Universidad de San Martín de Porres, Perú
}

\section{Resumen}

Se presenta las oportunidades y desafíos para el desarrollo de un turismo de carreteras en el Perú. El turismo, reduciéndolo, es movimiento. Y en el mundo, en el año 2016, se pudieron contabilizar 1235 millones de desplazamientos, según la Organización Mundial del Turismo (OMT, 2017c). Este movimiento utiliza, entre otros, las carreteras cuyo uso turístico favorece la construcción de la experiencia en el turista, dado el contacto directo con el paisaje y la libertad para desplazarse durante el tiempo y por los lugares deseados, y no necesariamente planificados. El Perú cuenta con una red vial bastante amplia y sus principales destinos se encuentran interconectados. Por ello, se plantea mirar con mayor atención el potencial del turismo de carreteras en consideración a la dinamización social y económica que podría generar. El turismo es una actividad de movimiento y, por lo tanto, debería aprovecharse el camino, ya no solo como un medio, sino como parte del fin.

Palabras clave: turismo, carreteras, experiencia turística, libertad, destino turístico, recurso turístico.

Este es un artículo Open Access bajo la licencia Creative Commons Atribución-NoComercial-Compartirlgual 4.0

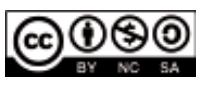




\begin{abstract}
This article presents the opportunities and challenges for the development of road tourism in Peru. In short, tourism is movement. According to the World Tourism Organization (WTO, 2017c), a total of 1,235 million arrivals were registered worldwide in 2016. This movement uses, among others, roads that create a better experience for tourists, due to the direct contact with the landscape and the freedom to move during the period of time and through the desired places that have not necessarily been planned. Peru has a very wide road network and its main destinations are interconnected. Therefore, this paper proposes to pay closer attention to the potential of road tourism in Peru, considering the social and economic dynamism it could generate. Tourism is an activity involving movement and, hence, roads should be used not only as a means, but also as part of the aim.
\end{abstract}

Keywords: tourism, roads, tourism experience, freedom, tourism destination, tourism resource.

\title{
Introducción
}

El turismo de carretera es una forma distinta de disfrutar de los beneficios del turismo, ya que puede, a diferencia del turismo tradicional, generar satisfacción en el viajero a partir del ejercicio de su libertad de decisión, reflejada, por ejemplo, en la flexibilidad para detenerse o incluso cambiar de rumbo en pleno camino.

Asimismo, este tipo de turismo puede generar oportunidades de desarrollo para las comunidades vinculadas al camino porque podrían aprovechar las paradas de los turistas para insertarse a la dinámica del turismo como proveedores de bienes y/o servicios: venta de alimentos, abarrotes y servicio de guiado son muestra de ello.

En el Perú, sus impresionantes paisajes, consecuencia de su variada geografía, así como sus diferentes culturas diseminadas por el territorio, tan ricas, milenarias en algunos casos y disímiles entre sí también por la misma variedad morfológica del territorio, se presentan como recursos turísticos 
que bien podrían ser disfrutados por el turista como parte de un recorrido. El Perú presenta entonces un potencial importante para el desarrollo del turismo de carreteras que, a lo largo del artículo, se irá sustentando.

\section{El turismo}

El turismo es una actividad de movimiento por antonomasia; es desplazarse para escapar, conocer(se) y/o descansar, entre otras motivaciones. Pero el movimiento va asociado a un interés aún mayor que el cambio de espacio en sí mismo. El gran motor, lo que atrae en realidad al turista, es justamente el atractivo turístico. En palabras de Aguiar (2010) el turismo es una «actividad social y económica, que promueve la movilización de las personas y la integración de los pueblos, con fines de recreación y esparcimiento para conocer y disfrutar los atractivos que ofrecen las distintas regiones» (p. 18); las dos dimensiones, líneas arriba mencionadas (social y económica), son las que el turismo de carreteras fomenta prioritariamente; pero estos puntos serán desarrollados con mayor detalle en la investigación.

Ahora bien, se sabe que en el turismo el qué (se visita) tiene el indiscutible protagonismo. Sin embargo, en el estudio se pretende poner bajo el faro el cómo del turismo, o sea, el cómo hacer para practicarlo o vivirlo, en concreto, la vía que comunica y las actividades que pueden ramificarse de esta, y los paisajes, lugares, comunidades $u$ objetos que ante el turista se presenten. El cómo se convierte en el qué.

El turismo es una actividad que es parte del día a día de nuestras sociedades líquidas (término acuñado por Zygmunt Bauman, 2005). Estamos frente a un mundo de mudanzas, de cambios, de estar sin estar (mediante los «desplazamientos virtuales»); un mundo en el que el turismo se convierte en uno de los últimos puntos de resistencia del desplazamiento y contacto físico, real, con el otro; y quizá ahí radique su protagonismo actual reflejado en las cifras de crecimiento: $4 \%$ promedio en los últimos siete años y un total de 1235 millones de desplazamientos el 2016 según la Organización Mundial del Turismo (OMT, 2017a). Es en ese sentido, también, que Bauman (2005) cree que «Urry tiene razón cuando desautoriza las profecías que auguran una inminente desaparición de los viajes, innecesarios gracias a la facilidad de las conexiones electrónicas. [Pues] el advenimiento de ese no 
lugar electrónicamente garantizado hace que los viajes resulten más atractivos, seguros y menos riesgosos que nunca» (pp. 86-87).

Las perspectivas que se tienen sobre el turismo, en tanto, apuntan a un crecimiento sostenido. Veamos: el año 1950, se calcula que por el mundo se dieron 25 millones de desplazamientos; recientemente la OMT, este organismo internacional especializado, publicó que en 2016 la cifra de desplazamientos alcanzó los 1235 millones. Y las proyecciones prometen 1300 millones al 2020 (OMT, 2017c).

Para fines prácticos presentamos la definición de turismo de la OMT (1999), ya que esta es parte del lenguaje universal que los involucrados en el sector manejan ${ }^{1}$, y porque además esta resalta la dimensión móvil del turismo, pues:

Comprende las actividades que realizan las personas durante sus viajes y estancias en lugares distintos al de su entorno habitual, por un periodo de tiempo consecutivo inferior a un año con fines de ocio, por negocios y por otros motivos. (p. 18)

\section{Turismo es desplazamiento}

El turismo es un fenómeno social de encuentro, según Severo (2007); de encuentro entre seres humanos que se buscan inconscientemente, que buscan conocer al otro y reconocerse en la diferencia con él; es también un fenómeno de desencuentro con el espacio de origen y con el diario quehacer, ciertamente. Lo que sí, es que el desplazamiento es ineludible, y que este es favorecido en un mundo en el que incluso estamos «llegando al punto en que las fronteras son meramente referenciales» (Alberca, 2014, p. 24), turísticamente hablando ${ }^{2}$.

1 No obstante, la inclusión de esta definición en el texto, creemos pertinente dejar expuesta nuestra posición sobre la misma. El turismo no debería incluir al turismo de negocios u de otro tipo que no tenga como motivación principal el ocio, el aprendizaje, el enriquecimiento personal y espiritual; es decir, el turismo se cree debe ser un fin y no algo accesorio.

2 Referenciales si se toma en consideración las facilidades administrativas relativas para desplazarse y el número de turistas desplazados cada año. Sin embargo, dadas las migraciones forzadas por temas religioso, políticos, étnicos, etc., muchos países, principalmente europeos (y que son a la vez destinos turísticos) han «endurecido sus fronteras». 
El turismo ha pasado por diferentes momentos en su abordaje. Inicialmente esta actividad fue entendida bajo un enfoque espacial, es decir, el énfasis estaba en el cambio de espacios como paradigma. Luego, los estudiosos miraron con atención a los flujos turísticos siendo estos los que definieron entonces la pauta de los estudios turísticos. Con el devenir del tiempo y tras la aplicación de la teoría de los sistemas a las ciencias sociales, el turismo se ve conceptualizado y comprendido como un sistema (Izaguirre, 2010).

En palabras de Oliveira Santos (como se citó en Izaguirre, 2010), quien es profesor e investigador de la Universidad de San Pablo (Brasil):

Las principales conceptualizaciones del turismo en el tiempo, han transitado desde su enfoque espacial al enfoque sistémico, en un afán por representar con precisión la realidad con el fin de lograr una mejor comprensión del turismo y una mejor calidad de la gestión de la actividad turística, contribuyendo al desarrollo del conocimiento académico del turismo. (p. 143)

En atención a lo recientemente expuesto, se revisarán dos modelos descriptivos del sistema turístico y pondremos énfasis en los caminos o vías de comunicación.

\section{El sistema turístico y las vías de comunicación}

En el turismo convergen diferentes actores: personas, asociaciones, infraestructuras, estructuras, lugares y otros que indudablemente deben estar comunicados virtual y físicamente; esto último plantea la siguiente pregunta: ¿esas vías de comunicación acaso podrían ser utilizadas ya no solo como parte de un simple recorrido obligado y de poco interés?

El turismo en consecuencia debe ser entendido como un sistema, pues no solo es el marco conceptual más adecuado, sino también el más actual. En ese sentido, el Instituto de Investigaciones Turísticas (como se citó en Jiménez \& Jiménez, 2013) describe a la actividad turística como «un conjunto definible de relaciones, servicios e instalaciones que interactúan cooperativamente para realizar las funciones que promueven» (p. 40). 
Pero el sistema turístico es abierto. Desde un enfoque geográfico, Jiménez y Jiménez (2013) dicen este está compuesto por dos grupos de elementos: intrínsecos y extrínsecos según su participación e incidencia, directa o indirecta, en el turismo.

Leiper (como se citó en Guerrero \& Ramos, 2014), resalta la existencia de tres regiones en el sistema turístico: las de origen, tránsito y destino. Dice asimismo que en la primera región se encuentran los «visitantes o turistas que se desplazarán o trasladarán en la región o ruta de tránsito representada por el sector transporte y donde se crea una interfase de conectividad, para acceder hasta una región de destino» (p. 69). Es decir, en este juego o cambio de regiones, en la intermedia, la de tránsito, se inserta el tema de las comunicaciones y el transporte. Sin embargo, para el propósito del presente escrito la presencia e importancia evidente de las vías de comunicación, no han de ser el medio, sino parte del fin, como ya se ha mencionado.

CONCEPCIÓN GEOGRÁFICA

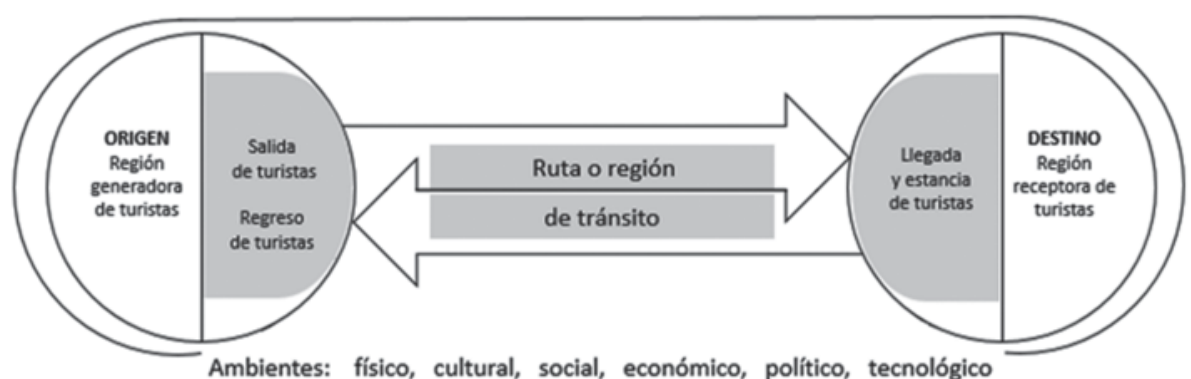

Ubicación de los viajeros, turistas y de la Industria del Turismo y de Viajes

Figura 1. Sistema turístico de Neil Leiper. Concepción geográfica. Fuente: Leiper (como se citó en Guerrero \& Ramos, 2014, p. 69).

Pero lo planteado por Leiper (como se citó en Guerrero \& Ramos, 2014), se cree, es pertinente para una visión macro del turismo, aunque no es suficiente. Es así que, si se analiza con mayor detalle el sistema, se tendría que: 
Como todo sistema, éste deberá ser abierto, es decir, con un feedback (realimentación) en el entorno que le rodea, con ello se logra una fluidez en sus objetivos y metas propuestas, los subsistemas que le conforman son: la estructura, infraestructura de recursos (atractivos y actividades turísticas), visitantes, el mercado tanto en la oferta como en la demanda, en las comunidades tanto emisoras como receptoras, y sobre todo el recurso humano requerido para funcionalidad, eficiencia y eficacia de todo el sistema. (p. 73)

Entonces, al leerse con detenimiento, puede verse y se ponen las luces encima, que se incluye al poblador receptor como parte integrante y presente del sistema. No se le deja de lado o se asume su inclusión de manera tácita. Y esto es importante porque el turismo de carretera no solo ha de beneficiar a los turistas con lo que puedan ver a lo largo del recorrido, sino que las comunidades del camino o de la región de tránsito, según el modelo de sistema turístico de Leiper (como se citó en Guerrero \& Ramos, 2014), se convertirían a su vez en receptoras y beneficiarias. No solo mirarían pasar los automóviles o buses, sino que los atenderían y compartirían. Pero este tema se retomará más adelante cuando se hable de la sostenibilidad vinculada al turismo de carreteras.

En esa misma dirección, es decir, con relación a la inclusión explícita de los receptores en el sistema, se retoma la definición de sistema como el conjunto de elementos que interactúan y que tienen un propósito general. En el caso del sistema turístico, ese objetivo si bien es la satisfacción del cliente, también, se cree, y en igualdad de importancia, lo es el beneficio de los receptores. Las dos caras de la misma moneda.

En consecuencia, véase la importancia de las vías de comunicación en el sistema turístico ya no solo como aquellos medios que conectarán el destino con los atractivos o bien dos espacios geográficos (origen y destino), sino como la posibilidad de crear un espacio turístico de disfrute, eso sí, con los beneficios asociados que este traería. Llegados a este punto, entender y definir el turismo de carreteras será el próximo tema a tratar. 


\section{El turismo de carreteras}

En los últimos 60 años aproximadamente, las aeronaves han experimentado un gran desarrollo tecnológico que ha permitido ir desplazando el uso del automóvil (y buses también) como medio para realizar viajes internacionales; para ser exactos, en el 2016 el 55\% de turistas, según la OMT (2017c), llegó a su destino por vía aérea. Sin embargo, mirando el viaje desde otra perspectiva se tiene que el transporte terrestre permite aprovechar el paisaje, la cultura y el clima de manera directa.

Se trata de una modalidad de turismo que consiste en la realización de prácticas turísticas durante el recorrido realizado entre dos o más espacios geográficos a través de un medio de trasportación terrestre, principalmente automóviles, de tal manera que el viajero puede disfrutar del paisaje y/o los recursos turísticos del camino con toda la libertad del tiempo y gustos personales.

Para este fin son importantes los paisajes, su belleza escénica para ser precisos, y atractivos turísticos de corte natural y/o cultural. A propósito, Urry (2004) dice que el turista durante sus viajes turísticos va coleccionando imágenes; en el caso del turismo de carreteras, se cree, estas van recogiéndose, viviéndose, en tiempo real y de manera más constante conforme se avanza en la carretera, es decir, el atractivo turístico es todo o gran parte del recorrido y no serán lugares entre cortados por espacios no turísticos como en el turismo convencional.

Asimismo, la infraestructura tanto vial como de recreación (léase paradores, carreteras, miradores, servicios higiénicos, entre otros) y la planta turística son importantes para la práctica y desarrollo del turismo de carreteras.

De otro lado, en este turismo las poblaciones vinculadas a las vías son relevantes ya que serán parte de la mirada del turista y quienes darán soporte a los viajeros pudiendo beneficiarse de la nueva opción turística.

Este turismo de carreteras es sumamente interesante entonces, pues es una forma de generar desarrollo en zonas rurales que, para mayores señas 
y actualidad, últimamente han sido relegadas (en la práctica y la teoría) por creerse erróneamente un tema superado en el Perú (Trivelli, 2017).

Y es que como las carreteras atraviesan zonas rurales, estas ya no se limitarían a ser solo parte de las vías de comunicación y medio de comercialización para sus poblaciones, sino que eventualmente podrían convertirse además en parte de, o en, un atractivo en sí mismo.

El Fondo Monetario Internacional en el año 2006 (como se citó en Pereira, Dos Santos, Torres, \& Tomasulo, 2012) en su estrategia para reducir la pobreza en República Dominicana sostenía que:

El turismo sustentable enriquece la vida de todos los ciudadanos por medio de la creación de oportunidades económicas, sociales y culturales, protegiendo los recursos naturales y escénicos y las herencias culturales del país, nutriendo el compromiso de la comunidad con el turismo a nivel sustentable por medio de la creación de carreras para la población. (p. 466)

Por otro lado, se debe entender que no toda carretera podrá ser turística por defecto. Lo serán las que presenten paisajes, pero sobre todo recursos turísticos relevantes, importantes, dignos del interés de los viajeros o, aquellas que unan espacios turísticos bastante frecuentados y que cumplan con las condiciones antes mencionadas, por lo que su creación o desarrollo debe ser pensado y estratégico.

Pero el turismo de carreteras no debe confundirse con los «corredores turísticos» de Boullón (2003), que no son otra cosa más que los caminos por donde se mueven los flujos turísticos con el fin de cumplir con sus itinerarios programados y que preferentemente deben pasar por donde los paisajes sean atractivos. O sea, en el caso del primero (turismo de carreteras) el camino es el fin y medio a la vez, además que la libertad de decisión y de uso del tiempo serán inherentes a él; mientras, que, en el segundo caso, el de los corredores turísticos, el camino es solo un medio, uno atractivo ciertamente, pero un medio al fin y al cabo, y además es un recorrido forzado pues tiene como propósito cumplir con ciertas «obligaciones» (léase visitas programadas). 


\section{La experiencia turística en movimiento}

La experiencia turística es una construcción individual, personal, y por lo tanto subjetiva. Partiendo de esta premisa se debe entender que la experiencia turística es en realidad la sucesión de una serie de experiencias resultado del «consumo» de servicios, y de la vivencia de momentos a lo largo del viaje turístico. Uno de esos «momentos» es la visita a los atractivos turísticos, corazón y razón de ser de los desplazamientos por turismo.

La libertad debe ser entendida como la capacidad de decidir y experimentar sin presión alguna, o, lo que es lo mismo, ser autónomo en cuanto a disponibilidad de tiempo y elección del espacio donde estar. Esta libertad puede ser un ingrediente importante en la definición de una experiencia, pues la satisfacción o la búsqueda de esta, dependerá exclusivamente de las decisiones del mismo turista, aunque claro, no queda exenta del servicio por recibir y de la influencia de este en la experiencia global. El turismo de carreteras apela a la libertad o autonomía justamente como característica principal y definitoria.

Se dirá que quien hace turismo de forma tradicional también es quien decide hacerlo o no y dónde, es decir es libre de decidir; sin embargo, la libertad a la que se alude al hablar del turismo de carretera tiene que ver con la de decidir qué hacer, dónde, cuándo y cómo; o sea, su desplazamiento y visitas no son parte de un producto establecido, sino que, es el turista mismo quien libremente «construye su producto» mientras va surcando los caminos que decidió, y eventualmente, va aun decidiendo tomar.

Además, el turismo de carreteras es un turismo que acerca al viajero con el paisaje, pues este turista no solo lo contemplará desde la ventana del automóvil o avión sino que tendrá la opción siempre que quiera, de «introducirse» en dicho paisaje, o sino de tomar el aire fresco que los espacios interurbanos (preferentemente naturales) ofrecen; o es más, podrá simplemente «estirarse» en medio del camino, con lo que, sea cual sea el motivo de su parada, suma a construir una sensación diferente, gratificante, cercana al paisaje. Es una forma de tener una experiencia turística en medio del movimiento del desplazamiento. 


\section{La sostenibilidad ambiental y social}

Si bien vivimos en un mundo cuyas condiciones ambientales futuras son cada vez menos predecibles, o lo que es lo mismo, es más incierto, dado el cambio climático, la humanidad, el hombre, ha mostrado sobradamente su gusto, y quizás, sin exagerar, su necesidad de viajar. El turismo mundial, por cierto, creció un promedio de $4 \%$ durante los últimos siete años (OMT, 2017a).

El cambio climático no es un fenómeno nuevo, y de eso sobran las evidencias no solo teóricas sino sobre todo fácticas. Sin embargo, lo que sí son relativamente nuevas son las causas: el hombre, sus actividades y su irresponsabilidad.

Sobre el cambio climático: es el resultado del calentamiento del planeta y, este, el resultado básicamente de la quema de combustibles fósiles que generan gases efecto invernadero (GEI) ${ }^{3}$. Rápidamente puede notarse que el turismo no está exento entonces de responsabilidad, aunque, por otro lado, sí tiene la oportunidad de ser el medio para el cambio y para la toma de conciencia.

La sostenibilidad ambiental tiene que ver con cómo utilizamos los recursos naturales y cómo nos relacionamos armónicamente con el entorno, de tal manera que podamos seguir viviendo, al menos, en las condiciones actuales y nuestros descendientes puedan hacer lo mismo.

Por el otro lado está la sostenibilidad social, que propugna, reduciéndola, que el turismo no debe afectar negativamente la vida social de los receptores, sino hacerlo de manera positiva generando oportunidades y respetando su cotidianeidad, su vida acostumbrada. Por ejemplo, si nos situamos en el primer escenario, mediante la participación de las comunidades en los proyectos de uso y desarrollo; y si nos ponemos en el segundo escenario, no alterando las formas de vida y paz social local (p. ej., a través de la venta y consumo de alcohol y drogas desmedido, prostitución, delincuencia, entre otros).

Vale aclarar que los combustibles fósiles no son los únicos responsables de la generación de GEI; lo son también la evaporación, la descomposición anaeróbica de vegetales y combustión de biomasa, la agricultura que usa fertilizantes nitrogenados, los aerosoles, otros. Los principales GEI son el metano, vapor de agua, óxido nitroso, clorofluorocarbonos y ozono. 
Para el caso del turismo de carreteras ambos pilares de la sostenibilidad son importantes, y están directamente vinculados a este.

El turismo como una actividad económica proveedora de servicios (pero que necesita infraestructura y planta para ello) tiene una huella de carbono, es decir, es responsable en parte de la emisión de gases de efecto invernadero (GEI) a la atmósfera (los GEI retienen el calor en la tierra), los que sin dudas provocan su calentamiento y consecuentemente los cambios en el clima; estos cambios tendrán consecuencias catastróficas para la humanidad.

El turismo, entonces, no está exento de la responsabilidad de emitir estos GEI; y la sumatoria de sus emisiones, o su huella de carbono, según la OMT (2017b) se calcula en alrededor del $5 \%$.

En relación a la responsabilidad de la actividad turística y el turismo de carreteras: este no solo debe ser sinónimo de autos circulando, sino del hecho de seguir una vía de comunicación como medio y fin, por lo que teóricamente el uso de trenes sería el ideal, pues así la contaminación y la huella del turismo sería menor, pero como ya se ha dicho, una característica fundamental es la libertad de parar y cambiar de planes eventualmente; libertad y flexibilidad que el tren no da, y que los automóviles sí.

No obstante la contaminación que podría producir el turismo de carreteras, habría que considerar que, al viajar en movilidades propias, el uso de autobuses o aviones se reduciría, aunque no significativamente, al menos al corto y mediano plazo, es decir, se cree que el consumo y emisiones no deberían verse exponencialmente aumentados. No obstante, el tema de la emisión, de la contaminación y uso de combustibles fósiles, es tarea pendiente ya no solo del sector turismo, sino de la humanidad en general $\mathrm{y}$ de los lideres mundiales en particular.

Por otro lado, el hacer turismo y relacionarse directamente con el clima y la naturaleza, con la gente y sus costumbres, puede ser una manera de tomar conciencia ambiental y cultural, y por ende de la biodiversidad y de la importancia del respeto del entorno; esto, dicho sea de paso, no está cuantificado: el tema no cuenta con data ni menos aún se ha comparado con las cantidades de emisiones. 
Con lo antes expuesto no se niega la contaminación adicional que este tipo de turismo pudiera producir, sin embargo, se cree que puede también ser una oportunidad para reflexionar al entrar en contacto libremente con el medio.

En lo referente a la sostenibilidad social, el desarrollo de paradores, por ejemplo, creará oportunidades para las poblaciones vinculadas al camino. Esto las hará participantes y beneficiarias. Será menester entonces de las autoridades locales el generar las condiciones para la participación de sus conciudadanos.

Asimismo, la «transitoriedad» de la visita puede atenuar el impacto social, pues en teoría no aparecerán actividades como consumo de drogas y alcohol, discotecas y bullicio hasta altas horas de la noche, ya que el turismo de carreteras consiste casi exclusivamente en mirar y avanzar. La vida social casi no se vería afectada.

En lo ambiental y social, entonces, el turismo de carreteras se presenta como sostenible y además como fuente de aprendizaje y enriquecimiento personal y de desarrollo para turistas y locales respectivamente.

\section{El turismo de carreteras, panorama mundial}

Antes que nada, habría que recordar que en el 2016 se registraron, según fuentes de la OMT (2017c), 1235 millones de desplazamientos; que el 53\% lo hizo con motivos de ocio, recreación y vacaciones, mientras que el $27 \%$ y $13 \%$, por motivos de salud, religión y negocios, respectivamente.

En el mismo 2016 el 55\% de los desplazamientos se dieron por vía aérea, el $41 \%$ por vía terrestre y el $4 \%$ por vía acuática. Sin embargo, para el presente texto es relevante que, del total de desplazamientos, el 39\% haya sido por carretera. Es decir, pese a las mayores facilidades en cuanto a costo (aerolíneas low cost, por ejemplo) y la relativa poca disposición de tiempo para un viaje turístico, es decir, poca disponibilidad de tiempo libre, hay un significativo porcentaje de turistas que prefieren utilizar la carretera como medio de comunicación y transporte; esto abona entonces al potencial del turismo de carreteras. 
En la Tabla 1 puede verse el comportamiento de los turistas respecto del uso del transporte terrestre como medio de desplazamiento. Vale decir que los datos presentados se refieren al medio utilizado para llegar al destino elegido.

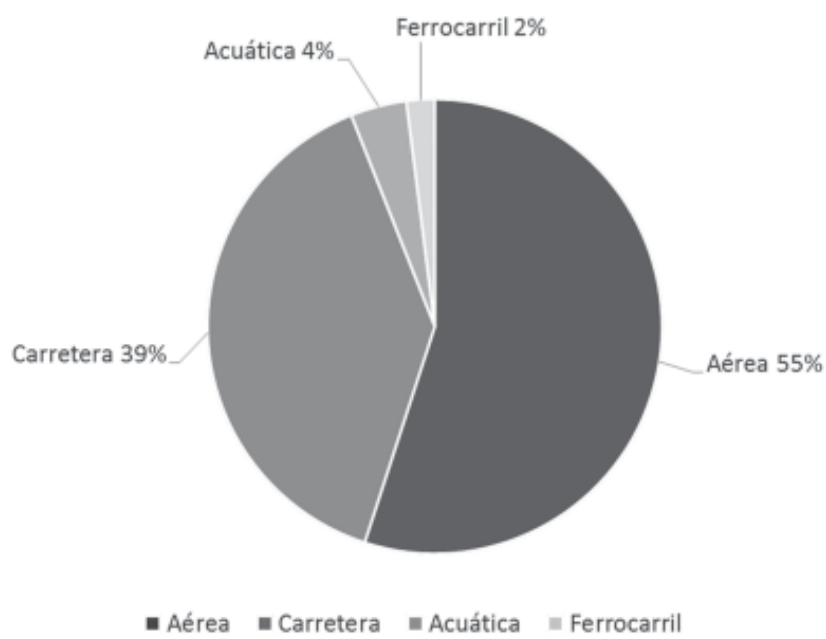

Figura 2. Turismo receptor por tipo de transporte, 2016.

Fuente: OMT (2017c).

\section{Tabla 1}

Desplazamientos a nivel mundial realizados por carreteras

\begin{tabular}{cc}
\hline Año & Porcentaje desplazamientos \\
\hline 2006 & $43 \%$ \\
2012 & $40 \%$ \\
2013 & $40 \%$ \\
2014 & $39 \%$ \\
2015 & $39 \%$ \\
2016 & $39 \%$ \\
\hline
\end{tabular}

Nota: OMT, 2007, 2013, 2014, 2015, 2016 y 2017c. 
En esta mirada al panorama mundial resalta también la tendencia a la eliminación de la necesidad de visas para realizar visitas, llegando el 2016 al porcentaje más bajo: 58\% frente al 61\% del año anterior (OMT, 2017a).

De lo mostrado puede colegirse que las facilidades se han ampliado y que recorrer destinos y traspasar fronteras en auto es también una posibilidad. No obstante, dependerá también de la infraestructura existente y seguridad.

La Organización Internacional de Constructores de Autos (OICA, por sus iniciales en francés, 2017), sostiene que al 2015, en el mundo había poco más de 1200 millones de vehículos en el mundo; la cifra ha venido creciendo desde el 2005 cuando el total era de 892028 millones, es decir, el parque automotor mundial crece, lo que representa una oportunidad para el turismo de carretera a escala mundial.

\section{El parque automotor en el Perú}

En el Perú, por su parte, siempre según la OICA (2017), en el año 2015 recorrían sus pistas 2.4 millones de vehículos. Según datos publicados el año 2016 en el diario especializado Gestión (2016) el parque automotor para ese mismo año crecería en alrededor de 100000 nuevos vehículos.

Para el año 2017, siguiendo la línea de crecimiento, Edwin Derteano (como se citó en Villalobos, 2016), presidente de la Asociación Automotriz del Perú, prevé que el mercado automotor crecería entre 5\% y $10 \%$ y que, además, este crecimiento sería liderado por la compra de camionetas SUV ${ }^{4}$ (mientras que la demanda de automóviles se mantendría constante).

Este último dato resulta interesante en la medida que estos vehículos SUV son más cómodos para viajes dadas sus dimensiones y equipamiento.

Gracias a sus ayudas a la conducción y a su avanzado sistema de adherencia a las superficies más difíciles, estos vehículos deportivos compactos, como también se les conoce, pueden desenvolverse por

4 Iniciales en inglés de Sport Utility Vehicle que en castellano significa Vehículo Utilitario Deportivo. 
igual tanto en la ciudad como fuera de ella (Off Road) (...) Además, su puesto de conducción elevado y su distancia con respecto al suelo hacen de los SUV unos coches muy seguros y manejables. (Peugeot.es, 2017)

Si bien no se sabe exactamente el porqué de la preferencia por este tipo de vehículos, esto no quita que sea una inferencia válida pensar que su compra masiva represente una oportunidad para la promoción del turismo de carreteras.

\section{Perfil del vacacionista nacional}

El turista interno y en particular el vacacionista nacional, tiene un comportamiento distinto al del turista receptivo cuando de transportarse se trata.

El gran porcentaje de estos turistas internos con motivos de recreación y vacaciones, según el Perfil del Vacacionista Nacional 2015 hecho por la Comisión de Promoción del Perú para la Exportación y el Turismo (PROMPERÚ, 2016), se desplaza por vía terrestre: alrededor del $89 \%$ frente a un $11 \%$ que lo hace por vía aérea. Este número de vacacionistas que se desplaza por tierra es interesante y una oportunidad si se correlaciona de alguna manera con las cifras de crecimiento del parque automotor y la mejora en las carreteras y caminos en general. Las posibilidades vistas en perspectivas parecen amplias, aunque de hecho hay que considerar otras variables como tiempo y costo.

Asimismo, de los que se desplazaron por tierra, se tiene que el $72 \%$ lo hizo en bus, $9 \%$ en auto propio y un $8 \%$ movilidad particular de un familiar/ amigo. En tanto, el $87 \%$ de los vacacionistas nacionales salieron de Lima, que se ubica en el centro del país y que además es la ciudad con mejor conectividad (Comisión de Promoción del Perú para la Exportación y el Turismo - PROMPERÚ, 2016).

Por otro lado, en cuanto a los grupos de viajeros, se tiene que el 38\% lo hace en grupo familiar directo, un $20 \%$ con amigos o familiares sin niños y un $19 \%$ en parejas. Además, se tiene que el $98 \%$ organizó su viaje totalmente por su cuenta (PROMPERÚ, 2016); dato este último que habla de la libertad 
y posibilidad de ser flexibles tanto en la programación del viaje, como en las actividades a realizar.

Se tiene, también, siempre según el Perfil del Vacacionista Nacional 2015 (PROMPERÚ, 2016), que el $84 \%$ se toma una semana o más en sus viajes (solo una 27\%). Entonces, se resalta aquí la existencia de disponibilidad de tiempo para el viaje. Asimismo, según PROMPERÚ (2016) se tiene que los principales destinos visitados por los vacacionistas son Lima, Ica, Piura, La Libertad, Junín, entre otros.

\section{Tabla 2}

Destinos más visitados por vacacionistas nacionales

\begin{tabular}{lc}
\hline Destino & Porcentaje vacacionistas \\
\hline Lima & $25 \%$ \\
Ica & $14 \%$ \\
Piura & $7 \%$ \\
La Libertad & $7 \%$ \\
Junín & $7 \%$ \\
Ancash & $7 \%$ \\
Arequipa & $5 \%$ \\
Lambayeque & $5 \%$ \\
Cusco & $5 \%$ \\
Cajamarca & $4 \%$ \\
\hline
\end{tabular}

Nota: Perfil del Vacacionista Nacional 2015 (PROMPERÚ, 2016).

De la Tabla 2, con la lista de los principales destinos visitados, podemos colegir que Lima e Ica concentran la mayor cantidad de visitas. Lima por ser la capital del país e Ica por estar cerca a Lima (primer emisor de turistas internos). No obstante, se puede apreciar que la zona norte del Perú y la sierra central son regiones también bastante visitadas. En todo caso, lo importante es ver que los principales destinos se encuentran conectados por carreteras principales como la Panamericana norte y sur y la carretera central o la alterna Cañete - Yauyos - Huancayo, que del mismo modo llega al centro 
del país, pero sobre este tema se volverá más adelante, pues evidentemente las mencionadas no son las únicas carreteras principales y con potencial para vertebrar el desarrollo del turismo de carreteras.

Una vez más el Perfil del Vacacionista Nacional 2015 brinda información valiosa. Así, se tiene que el $22 \%$ de los viajeros tiene auto propio; y de ellos $23 \%$ afirma viajar casi siempre en su auto y 53\% a veces (PROMPERÚ, 2016). Vale decir que existe un pequeño número de viajeros acostumbrados a desplazarse en sus propios vehículos; pero si se mira a los que no, se presenta una oportunidad, pues en gran número no descartan hacer el viaje de esa forma. Se puede sumar a este análisis el crecimiento del parque automotor ya reseñado.

Finalmente, el análisis que se hace en el presente artículo, como puede verse, se ha enfocado en los vacacionistas nacionales, es decir, quienes se desplazan por motivaciones de vacaciones y recreación (4.6 millones de viajes) (PROMPERÚ, 2016). Las inferencias hechas en este acápite, en todo caso, bien podrían ampliarse considerando al turismo interno en general, sin importar sus motivaciones (pues son los vacacionistas en particular, y los turistas internos en general, quienes tienen mayor disponibilidad de vehículos particulares y conocimiento de los destinos y carreteras), ya que suman aproximadamente 16 millones de desplazamientos (Observatorio Turístico del Perú - OTP, 2017), con todo lo que ello implica.

\section{El Perú, sus carreteras y los destinos turísticos por los que pasan}

Si bien el Perú es un país con una geografía complicada, lo que representa un reto importante cuando de conectividad terrestre se trata, tiene una importante y amplia red de carreteras que permite unirlo.

Las principales carreteras son la Panamericana (norte y sur) que va de Tumbes a Tacna, la Longitudinal de la Sierra (desde Puesto Vado Grande en Ayabaca, Piura, hasta Desaguadero en Puno) y la Marginal de la Selva (desde San Ignacio en Cajamarca hasta Puerto Pardo en Madre de Dios); estas carreteras cruzan el país verticalmente y se conectan con otras vías de penetración que justamente se internan llegando a poblados más lejanos (Ministerio de Transportes y Comunicaciones del Peru - MTC, 2017c). 
Atraviesan horizontalmente el territorio las carreteras IIRSA ${ }^{5}$ norte y sur: la primera que va desde Paita o Lambayeque (dos puntos de origen) hasta Yurimaguas (Loreto), y la segunda que va de Urcos (en Cusco) hasta la frontera con el Brasil en la región Madre de Dios.

Por otro lado, en el Perú la red vial nacional, al año 2012, según datos del Ministerio de Transportes y Comunicaciones del Perú (2017a), tenía un total de 24593.40 kilómetros (entre asfaltada, afirmada y sin afirmar); mientras que las vías departamentales 24235.12 kilómetros en total.

De cara al turismo, si se miran los trazos de las vías nacionales, puede verse no solo que hubo un proceso importante de pavimentación de las vías, sino que los destinos turísticos más importantes del Perú se encuentran interconectados por estas: los de la costa norte, Lima, la sierra central y el sur del país, los destinos del sur entre ellos, toda la costa, toda la sierra. Además, como puede apreciarse, la comunicación puede darse de manera vertical, horizontal e intrarregional.
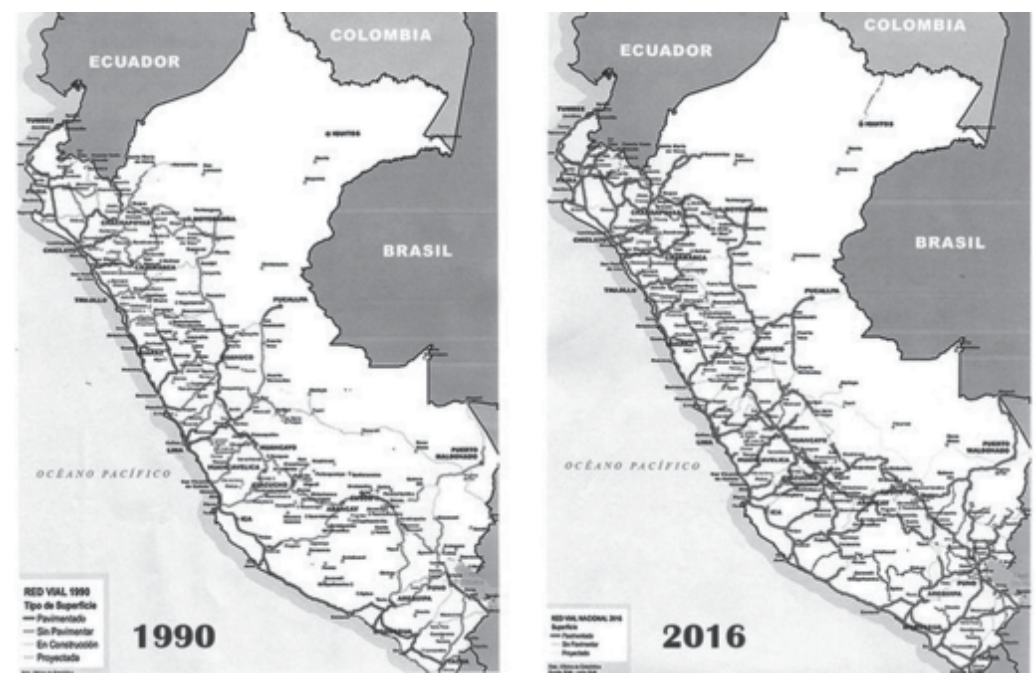

Figura 3. Red vial nacional comparada entre 1990 - 2016.

Fuente: Ministerio de Transportes y Comunicaciones del Perú (2017a).

5 Más conocidas como «interoceánicas». IIRSA, iniciales de Iniciativa de Integración Regional Sudamericana. 


\section{Conclusiones: oportunidades y desafíos}

Sobre las oportunidades, el Perú es un país privilegiado por los paisajes que la geografía le ha regalado y que además son valorados por los vacacionistas nacionales: $46 \%$ considera los paisajes y la naturaleza para decidir viajar y un 27\% considera el clima cálido (PROMPERÚ, 2016). Entonces, para un mejor disfrute se recomienda realizar ese viaje por carretera teniendo así un contacto más cercano, directo, con ese paisaje que motiva, dada la posibilidad de realizar paradas durante el recorrido.

El turismo de carreteras tiene como principales características la libertad y flexibilidad para modificar el recorrido del viaje, por lo que la experiencia turística podría verse potenciada dada la autonomía de decisiones.

En tanto, en el Perú hay una creciente demanda de compra de automóviles, en particular, SUV. Se suma a ello, que las vías nacionales y de penetración, en líneas generales, logran cubrir gran parte del territorio, pero sobre todo, permiten llegar a los principales destinos turísticos nacionales; eventualmente las condiciones podrían sugerir la viabilidad de un desarrollo de turismo de carreteras en el Perú.

Por último, los vacacionistas nacionales suelen viajar en grupos (familia o amigos) haciendo que la posibilidad de un viaje por carreteras sea además una oportunidad para compartir.

En cuanto a los desafíos se ha observado, inicialmente, que no existe la masiva costumbre de viajar por carreteras en auto propio y que el tema de seguridad y seguridad vial en las carreteras está aún pendiente ${ }^{6}$; la solución a este último punto debe ser abordada multisectorialmente, ya que es un tema que escapa de la responsabilidad directa del sector turismo.

Se recomienda entonces, aprovechar el potencial que el Perú presenta para el turismo de carreteras; para ello, se sugiere al sector público y privado vinculado al turismo considerar las siguientes acciones:

6 Sobre seguridad en las carreteras, en el 2014 en el 2016 se reportaron 156 asaltos, siendo la mayoría a buses y camiones (MTC, 2017b). Sobre seguridad vial, el MTC presentó el Plan Estratégico Nacional de Seguridad Vial 2017-2012 con el fin de reducir en un 30\% y 50\% los accidentes al 2021 y 2025 respectivamente. 
- Promover el uso de las carreteras ya no solo como medio, sino como un fin en sí mismo; como la oportunidad de gozar del viaje, no solo del destino (sector público).

- Exponer los beneficios del turismo de carreteras como mecanismo de desarrollo fundamentalmente en zonas rurales (sector público).

- Priorizar rutas o recorridos con mayor potencial turístico, por ejemplo, la Interoceánica Norte, que va desde Paita, Piura, hasta Yurimaguas en Loreto (sector público).

- Señalizar adecuadamente los recorridos que fueran priorizados para facilitar el conocimiento, acceso y disfrute.

- En las rutas a priorizar, evaluar la implementación de corredores turísticos preferenciales.

- Invertir en infraestructura que sea útil para este tipo de turismo como paradores turísticos, zonas de descanso (sector público) y grifos (sector privado), entre otros.

- Promover que las poblaciones vinculadas a los caminos se inserten en la dinámica del turismo participando como proveedores de bienes y servicios (sector público).

- Acompañar la renta de autos con propuestas de recorridos con paradas de interés turístico que se puedan convertir en productos turísticos (sector privado). 


\section{Referencias}

Aguiar, A. (2010). Turismo Sostenible. El Turismo como estrategia de desarrollo socioeconómico. Caracas: Free Zone.

Alberca, F. (2014). Potencial turístico de Ayabaca como destino cultural. Una nueva metodología (Tesis de maestría). Universidad de San Martín de Porres, Lima, Perú.

Bauman, Z. (2005). Amor líquido. Acerca de la fragilidad de los vínculos humanos. Buenos Aires: Fondo de Cultura Económica.

Boullón, R. (2003). Planificación del espacio turístico. México DF: Trillas.

Comisión de Promoción del Perú para la Exportación y el Turismo - PROMPERÚ. (2016). Perfil del Vacacionista Nacional 2015. Lima: PROMPERÚ.

Gestión. (15 de junio de 2016). Parque automotor del Perú subirá a 2.6 millones de vehículos en 2016. Gestión. Recuperado de http://gestion.pe/empresas/parque-automotor-peru-subira-26-millones-vehiculos2016-2163406

Guerrero, P., \& Ramos, J. (2014). Introducción al turismo. México, DF: Grupo Editorial Patria. Recuperado de http://www.ebrary.com

Izaguirre, M. (2010). El turismo en el contexto de las sociedades complejas. Cultura, 24, 141-163.

Jiménez, L., \& Jiménez, W. (2013). Turismo: tendencias globales y planificación estratégica. Bogotá: Ecoe Ediciones. Recuperado de http://www.ebrary.com

Ministerio de Transportes y Comunicaciones - MTC. (2012). Sistema Nacional de Carreteras del Perú (Informe GTT - II semestre dic. 2012). Recuperado de http://www.mtc.gob.pe/transportes/caminos/documentos/ RESUMEN_GENERAL_2012.pdf

Ministerio de Transportes y Comunicaciones del Perú - MTC. (2017a). Recuperado de http://www.mtc.gob.pe/ transportes/5caminos/normas_carreteras/mapa-ruta-nacional.html

Ministerio de Transportes y Comunicaciones del Perú - MTC. (2017b). Infraestructura. Servicios. Asaltos. Recuperado de http://www.mtc.gob.pe/estadisticas/transportes.html

Ministerio de Transportes y Comunicaciones del Perú - MTC. (2017c). Mapas Viales por Rutas Nacionales. Recuperado de http://www.mtc.gob.pe/transportes/caminos/normas_carreteras/mapa-ruta-nacional.html

Observatorio Turístico del Perú - OTP. (9 de setiembre de 2017). BADATUR. Perú: Turismo Interno 1992 2016. Lima: USMP - EPTH. Recuperado de http://www.observatorioturisticodelperu.com/mapas/tinterno.pdf

Organización Internacional de Constructores de Autos - OICA. (2017). World Vehicles In Use - All Vehicles 2005 - 2015. Recuperado de http://www.oica.net/wp-content/uploads//PC_Vehicles-in-use.pdf

Organización Mundial del Turismo - OMT. (1999). Guía para administradores locales: Desarrollo turístico sostenible. Madrid: OMT.

Organización Mundial del Turismo - OMT. (2007). UNWTO Tourism high lights. Madrid: OMT.

Organización Mundial del Turismo - OMT. (2013). UNWTO Tourism high lights. Madrid: OMT.

Organización Mundial del Turismo - OMT. (2014). UNWTO Tourism high lights. Madrid: OMT.

Organización Mundial del Turismo - OMT. (2015). UNWTO Tourism high lights. Madrid: OMT.

Organización Mundial del Turismo - OMT. (2016). UNWTO Tourism high lights. Madrid: OMT.

Organización Mundial del Turismo - OMT. (2017a). Annual Report 2016. Madrid: OMT.

Organización Mundial del Turismo - OMT. (2017b). Conferencia Mundial sobre «El turismo y la energía del 
futuro: en busca de oportunidades de crecimiento con bajas emisiones de carbono». UNWTO News, 64. Recuperado de http://media.unwto.org/es/content/unwto-news-64

Organización Mundial del Turismo - OMT. (2017c). UNWTO Tourism high lights. Madrid: OMT.

Pereira, J., Dos Santos, P., Torres, L., \& Tomasulo, S. (2012). El paisaje de la carretera Interpraias en el balneario Camboriú (Santa Caterina, Brasil) según la perspectiva turística de las carreteras parques. Estudios y perspectivas en turismo, 21(2), 461-477. Recuperado de http://www.scielo.org.ar/ scielo.php?script=sci_arttext\&pid=\$1851-17322012000200011\&lng=es\&tlng=es

Peugeot.es. (2017). ¿Qué es un SUV? Recuperado de http://www.peugeot.es/que-es-un-coche-suv/

Severo, L. (2007). Turismo e globalização: algumas perspectivas. Revista Iberoamericana de Estratégia, 6(1), 63-70. Recuperado de http://www.redalyc.org/pdf/3312/331227109007.pdf

Trivelli, C. (4 de setiembre de 2017). Retomar lo rural. Perú 21. Recuperado de https://peru21.pe/opinion/ opina21-carolina-trivelli/carolina-trivelli-retomar-rural-374409

Urry, J. (2004). La mirada del turista. Lima: Universidad de San Martín de Porres - Escuela Profesional de Turismo y Hotelería.

Villalobos, M. (9 de diciembre de 2016). AAP: Mercado automotor crecería entre 5\% y $10 \%$ en el 2017 . El Comercio. Recuperado de: http://elcomercio.pe/economia/peru/aap-mercado-automotor-creceria-5-10-2017229878 